\title{
Urgences
}

\section{Les mots ont donc fait...}

\section{Renald Bérubé et André Gervais}

Numéro 15, octobre 1986

Épigraphiques

URI : https://id.erudit.org/iderudit/025333ar

DOI : https://doi.org/10.7202/025333ar

Aller au sommaire du numéro

Éditeur(s)

Urgences

ISSN

0226-9554 (imprimé)

1927-3924 (numérique)

Découvrir la revue

Citer ce document

Bérubé, R. \& Gervais, A. (1986). Les mots ont donc fait... Urgences, (15), 71-71.

https://doi.org/10.7202/025333ar d'utilisation que vous pouvez consulter en ligne.

https://apropos.erudit.org/fr/usagers/politique-dutilisation/ 
Tout a été dit. Sans doute. Si les mots n'avaient changé de sens; et les sens, de mots.

Jean Paulhan: Clef de la poésie

Les mots ont donc fait leur travail, travail sur les mots. Le(s) sens de même, de pair avec les mots, travail lié.

Tout demeure toujours à dire, c'est-à-dire à redire. Par chacun et par chacune, selon les temps, les lieux.

À toutes celles et à tous ceux qui, le sachant ou ne le sachant pas, auteur(e)s des épigraphes - d'Émile Ajar à Josée Yvon en passant par Henri Laborit, Willie Lamothe, Virginia Woolf et bien d'autres encore - ou des textes mis à l'oeuvre ou en oeuvre par lesdites épigraphes; à toutes celles et à tous ceux, donc, qui ont répondu à notre (votre) invitation et/ou (!) collaboré à ce numéro, un mot, simple, bref comme il va de soi, chaleureux: merci.

R.B. / A.G. 